\title{
Serviços de Garantia dos Direitos de Crianças e ADOLESCENTES: DEMANDAS E ENCAMINHAMENTOS
}

\section{Services that Guarantee the Rights of Children and Adolescents: demands and referrals}

\author{
Rosângela Francischini* \\ Deliane Macedo Farias de Sousa* \\ Joana Fontes Patiño**t
}

\begin{abstract}
RESUMO
O Estatuto da Criança e do Adolescente dispõe, dentre as medidas de proteção integral a essa parcela da população, o direito à convivência familiar e comunitária. Ocorre que, por vezes, os contextos de desenvolvimento, principalmente a família, no lugar de serem espaços de proteção, constituem-se enquanto espaços de violação de direitos, caracterizando-se enquanto contextos de risco. Nessas condições, são acionados os Serviços de Garantia dos Direitos de Crianças e Adolescentes que vêm, progressivamente, ganhando visibilidade social. Esta visibilidade vem tornando explícita a atuação dos organismos (governamentais ou não) responsáveis por esses serviços diante das demandas que lhes são colocadas. Com o objetivo de identificar algumas dessas possibilidades, realizou-se uma pesquisa com alguns dos principais responsáveis pelos referidos serviços, em Natal. Dos resultados observados, destacam-se as denúncias e atendimentos relacionados à violência intrafamiliar: violência física, negligência e abuso sexual, principais focos de atenção neste trabalho.
\end{abstract}

Palavras-chave: violência intrafamiliar; crianças; direitos.

\begin{abstract}
Amongst the integral protection measures proposed in the Child and Adolescent Statute (CAS), it is warranted the right of that parcel of population to live with their family and community members. Nevertheless, sometimes, the development contexts, mainly the family, on the contrary to be protection spaces, configure it like spaces where rights are violated, becoming risk scenarios. In such conditions the services that guarantee the rights of children and adolescents are activated, which have been gaining, progressively, social visibility. That visibility has becoming explicit the work of the organization (governmental or not) responsible for those services in face of the demands that they received. Aiming at identifying some of those possibilities, a research was accomplished with some of the main organizations responsible for those services in Natal city. From the results observed, the following accusations and pleads regarding violence into the family are detached: physical violence, negligence and sexual abuse, that are the main attention focuses of this paper.
\end{abstract}

Keywords: violence into the family; children; rights.

\footnotetext{
Rosângela Francischini é Prof ${ }^{a}$. da Universidade Federal do Rio Grande do Norte. Coordenadora do Núcleo de Estudos Socioculturais da Infância e Adolescência. Coordenadora do Gt Desenvolvimento Humano em Situação de Risco Social e Pessoal da Associação Nacional de Pesquisa e Pós-Graduação em Psicologia. E-mail: rfranci@uol.com.br.

** Deliane Macedo Farias de Sousa é Psicóloga formada pela Universidade Federal da Paraíba. É aluna do Programa de Pós-Graduação em Psicologia (Mestrado) da UFRN, bolsista da CAPES, desenvolvendo projeto de pesquisa sobre a condição de infância vivenciada por crianças inseridas na exploração sexual comercial.

**** Joana Fontes Patiño é Psicóloga, formada pela Universidade Federal do Rio Grande do Norte. É aluna do Programa de Pós-Graduação em Psicologia (Mestrado) da UFRN, bolsista da CAPES, desenvolve projeto de pesquisa sobre Direitos da Criança considerando a percepção dessa população. Foi estagiária do Conselho Estadual de Direitos da Criança e do Adolescente.
} 


\section{RESUMEN}

El Estatuto del Niño y del Adolescente dispone, dentro de las medidas de protección integral a esa franja de la población el derecho a la convivencia familiar y comunitaria. Sucede que, algunas veces, los contextos de desarrollo, principalmente el espacio familiar, en lugar de seren espacios de protección, se transforman en espacios de violación de los derechos, caracterizándose como contextos de riesgo. En estas condiciones, son accionados los servicios de Garantía de los Derechos del Niño y del Adolescente, que vienen, progresivamente, ganando visibilidad social. Esta visibilidad viene tornando explícita la actuación de los organismos (estatales o no) responsables por estes servicios delante de las demandas que les son colocadas. Con el objetivo de identificar algunas de esas posibilidades, se realizó una investigación con algunos de los principales responsables por los referidos servicios, en Natal. De los resultados observados, se destacan las denuncias a la atención relacionada a la violencia intrafamiliar: violencia física, negligencia y abuso sexual, principales focos de atención de este trabajo.

Palabras-clave: violencia intrafamiliar; niños; derechos.

\section{O Estatuto da Criança e do Adolescente} (ECA), Lei 8.069/90, que dispõe, no Brasil, sobre os direitos dessa parcela da população, regulamentando, assim, o que foi estabelecido no art. 227 da Constituição da República e na normativa internacional pertinente, especifica que a criança é um sujeito em condição especial de desenvolvimento e que deverá estar protegida de toda forma de violência, agressão, negligência, dentre outras ações que possam prejudicar esse desenvolvimento. Nesse sentido, é proposto pelo ECA um conjunto de ações - Sistema de Garantias, conforme Faleiros (2006) - que objetiva a Garantia dos Direitos de Crianças e Adolescentes, que é composto por organismos e instituições públicas (esferas Federal, estaduais e municipais) e não governamentais.

Com o objetivo de conhecer como funciona parte dos serviços responsáveis pela garantia dos direitos da criança e do adolescente, no município de Natal, capital do Rio Grande do Norte, foi realizada uma pesquisa com algumas dessas instituições, a saber: Programa Sentinela, Delegacia de Proteção à Criança e Adolescente vítimas de violência e SOS Criança. Portanto, o objetivo deste trabalho é apresentar um recorte dos resultados dessa investigação, explicitando as principais demandas que são colocadas aos serviços de proteção às crianças e adolescentes e os encaminhamentos que são efetuados a partir dessas demandas.

\section{Contextualizando o tema}

O Estatuto da Criança e do Adolescente (ECA), promulgado em 1990 a partir de ampla mobilização e participação da sociedade civil no processo de sua elaboração, constitui-se, sem sombra de dúvida, na principal conquista, no plano legal, relacionada aos direitos de crianças e adolescentes. Ao abandonar o paradigma da "infância em situação irregular" e adotar o princípio da "proteção integral", prescreve sobre os deveres e responsabilidades do Estado, da família e da sociedade civil para com todos os cidadãos menores de 18 anos (BAZÍlLIO e KRAMER, 2003). Nesse sentido, além da regulação dos princípios básicos relacionados aos direitos dessa parcela da população, aponta para os atores sociais responsáveis pela promoção, proteção, controle e defesa desses direitos. Estrutura-se, então, um conjunto articulado de ações - Sistema de Garantia dos Direitos de Crianças e Adolescentes (FALEIROS, 2006) - composto, de acordo com o referido autor, pelos seguintes organismos:

- Conselhos de Direitos da Criança e do Adolescente

Em níveis nacional, estadual $e$ municipal, são órgãos do poder executivo, deliberativos e controladores das ações nesses três níveis. Sua composição é paritária (poder público e sociedade civil) 
- Conselhos Tutelares

Órgãos públicos municipais, os Conselhos Tutelares são os principais organismos responsáveis pelo zelo no cumprimento dos direitos das crianças e dos adolescentes. "Têm caráter permanente e gozam de autonomia hierárquica no cumprimento de suas competências e atribuições, ou seja, não estão vinculados aos Conselhos de Direitos nem à Secretaria de governo a que pertencem" (FALEIROS, 2006, p. 140). ${ }^{1}$ Em artigo intitulado O Estatuto da Criança e do Adolescente está em risco? Os Conselhos Tutelares e as medidas socioeducativas, Bazílio (2006) afirma:

Embora alguns municípios venham trabalhando de forma responsável, dando suporte às ações/determinações de seus membros, a grande parte destes órgãos encontra-se funcionando de forma precária. Seja por ignorância do texto legal por parte da população ou autoridades, seja por descaso, o Estatuto da Criança e do Adolescente consegue ser ao mesmo tempo desconhecido e criticado. (2006, p. 40)

Dentre os principais problemas enfrentados por aqueles que recorrem aos serviços dos Conselhos, Bazílio destaca:

a) falta de estrutura (física, material e apoio) para atender à real demanda das violações de direitos. (...) b) Ausência de capacitação e/ou qualidade dos treinamentos oferecidos. (...) c) Questões relativas à representação política do conselheiro. (...) d) Falta de retaguarda ou estrutura de apoio. (...) e) Excesso de solicitações de demanda direta (encaminhamentos, atendimentos) prejudicam funções de fiscalização e supervisão dos abrigos e demais entidades que prestam atendimento à infância. (BAZÍLIO, 2006, p. 40-43)

\section{Adolescente}

- Fundos dos Direitos da Criança e do

Assim como os Conselhos de Direitos, os Fundos são instrumentos existentes nos níveis federal, estaduais e municipais e têm como função a gestão e o controle dos recursos, provenientes dos orçamentos públicos ou não, destinados ao atendimento dos direitos de crianças e adolescentes.

- Varas da Infância e da Juventude

Como o Estatuto prevê a aplicação de medidas judiciais, as Varas da Infância e da Juventude foram estruturadas com a função de aplicação dessas medidas.

Juventude

- Promotorias da Infância $e$

"São órgãos do Ministério Público que têm como função institucional defender $e$ assegurar os direitos fundamentais de crianças e adolescentes, através da aplicação de medidas judiciais previstas no ECA" (FALEIROS, 2006, p. 142).

- Fóruns dos Direitos da Criança e do Adolescente (Fórum DCA)

Considerando que um dos princípios do Estatuto é a articulação, em redes, para garantia dos direitos de crianças e adolescentes, os fóruns reúnem atores, grupos e instituições, governamentais ou não, mantendo o pressuposto da articulação entre eles na perspectiva de garantia, de forma integrada, desses direitos.

- Delegacias de Proteção à Criança e ao Adolescente (DPCA)

São órgãos da Segurança Pública que exercem a função de polícia judiciária, cabendo-lhes a apuração, através de Inquérito Policial, de ilícitos cometidos contra crianças e adolescentes.

\footnotetext{
1 FALEIROS, V. de P. Formação de educadores(as): subsídios para atuar no enfrentamento à violência contra crianças e adolescentes. Brasília: MEC/SECAD; Florianópolis: UFSC/SEaD, 2006.
} 
Considerando que esse organismo está incluído no recorte que fizemos nesta pesquisa, será retomado de forma mais detalhada, posteriormente, quando da apresentação das demandas e intervenções.

- Centros de Defesa - organizações não-governamentais

- Defensoria Pública - garantia dos direitos de assistência jurídica

- Polícia Militar

Com a função de segurança pública, comunica ao Conselho Tutelar e à Delegacia Especializada a violação dos direitos de crianças $e$ adolescentes.

- Serviços Sentinelas

Visando atender as diretrizes propostas pelo ECA e pela Lei Orgânica de Assistência Social, no que diz respeito à rede de garantia dos diretos da criança e do adolescente, os Serviços Sentinelas constituem-se enquanto "ação da Política de Assistência Social que compõe os Centros de Referência de Assistência Social Especializados, coordena a prestação de serviços multiprofissionais dirigidos a crianças, adolescentes e famílias envolvidas com a violência sexual" (FALEIROS, 2006, p. 144). Atualmente, segundo dados de Faleiros (2006), estão presentes em mais de 1.100 municípios brasileiros.

Além do Programa Sentinela, destacamos o Programa de Ações Integradas e Referenciais de Enfrentamento à Violência Sexual Infanto-Juvenil no Território Brasileiro - PAIR, elaborado em 2002 pelos seguintes organismos: Secretaria de Estado de Assistência Social (na época, do Ministério da Previdência e Assistência Social), Secretaria de Estado dos Direitos Humanos (naquele período, vinculada ao Ministério da Justiça; atualmente é uma Secretaria Especial vinculada diretamente à Presidência da República), Agência dos Estados Unidos para o Desenvolvimento Internacional (USAID) e Partners of the America. Sua implantação deu-se em junho do mesmo ano, em seis municípios brasileiros selecionados em decorrência dos indicadores de violência e exploração sexual e tráfico de crianças e adolescentes para fins sexuais, observados em pesquisa nacional sobre o Tráfico de Mulheres, Crianças e Adolescentes para fins de Exploração Sexual, realizada pelo Ministério da Justiça, em 2002.

Atualmente, o PAIR está em processo de expansão; em 2006 a Secretaria Especial de Direitos Humanos e o Fórum Nacional de Pró-Reitores de Extensão das Universidades Públicas assinaram um termo de Cooperação Técnica visando ações conjuntas e de apoio, por parte das Instituições Públicas Federais de Ensino Superior, no enfrentamento da violência e exploração sexual comercial contra crianças e adolescentes.

Assim como a Delegacia Especializada, o Programa Sentinela será explanado mais adiante, uma vez que dentre os organismos componentes do Sistema de Garantia dos Direitos da Criança e do Adolescente o Sentinela fará parte deste trabalho.

- Conselho Comunitário de Defesa Social

- Secretarias de Governo Estaduais e Municipais executoras de Políticas Públicas

São considerados organismos fundamentais e têm a "função de atendimento, ou seja, de garantir o acesso à saúde, educação, assistência, cultura, profissionalização e proteção especial (...)" (FALEIROS, 2006, p. 144).

Em relação a essa última função, de proteção especial, destacam-se as ações das Secretarias de Ação Social, dentre elas, as que são objeto de abordagem neste trabalho, quais sejam, os serviços de atendimento às crianças e adolescentes vítimas de violência, principalmente violência intrafamiliar, prestados pelo programa S.O.S. Criança.

- Organizações não-governamentais

Como pode ser observado nos itens relacionados acima, em que são explicitados os múltiplos organismos componentes do sistema de garantia dos direitos da criança e do 
adolescente, há organismos nas esferas federal, estaduais e municipais, com funções e objetivos específicos, muito embora não se possa desconsiderar a proposta de atuação articulada entre esses organismos.

Neste contexto é que se insere o objetivo principal deste artigo, qual seja, identificar quais são as demandas principais que compóem o quadro de atendimento de três desses organismos que, muitas vezes, acabam por resultar em encaminhamentos para a medida de abrigamento ${ }^{2}$. Optamos por apresentar e discutir esses dados paralelamente, focalizando instituições que, por sua natureza, atendem diretamente crianças e adolescentes vítimas de violência. Portanto, a estrutura deste trabalho reflete a opção por uma inter-relação entre teoria e prática da pesquisa, considerando algumas questões da reflexão teórica produzida na área e os dados apresentados pelas instituições.

\section{As demandas e intervenções}

\section{Programa Sentinela}

Em relação ao Sentinela - Programa de Enfrentamento ao Abuso e Exploração Sexual contra Crianças e Adolescentes - observamos que se trata de uma iniciativa governamental, em parceria com os municípios, que tem por objetivo o atendimento de crianças e adolescentes vítimas do abuso sexual e exploração sexual comercial, bem como o atendimento das famílias desses sujeitos. O abuso sexual se configura, de acordo com a Abrapia (1992), como sendo uma situação onde a criança ou adolescente é usado por um adulto ou mesmo um adolescente mais velho, com a finalidade de satisfação sexual destes últimos, através da manipulação da genitália, mama ou ânus do abusado.

Assim, o Sentinela busca, conforme comunicação da Coordenação local ${ }^{3}$,

[...] propiciar o atendimento a crianças e adolescentes vítimas de abuso e exploração sexual, buscando o fortalecimento daauto-estimadestes, bem como lhes proporcionando alternativas de vida que lhes permitam construir um processo coletivo, garantindo-lhes seus direitos de cidadania com dignidade e respeito (cf. nota 2).

No município de Natal, está vinculado à Secretaria Municipal de Trabalho e Assistência Social, mais especificamente ao Departamento de Proteção Social Especial.

Segundo dados do Programa, os principais abusadores são pessoas do espaço familiar (principalmente pais e padrastos), portanto, próximos à criança ou adolescente, $e$ que mantêm com ela uma relação de confiança e/ou de poder. Essa mesma constatação será observada posteriormente, na discussão das demandas da Delegacia Especial de Proteção à Criança e ao Adolescente, vítimas de violência. Uma outra característica dessa violação dos direitos da criança é que ela costuma não ter testemunhas ou, quando as tem, elas se colocam enquanto cúmplices da violência. Em trabalho recente, e de extrema importância nesta discussão, Catarina Schmickler (2006) observa que os agressores, com o objetivo de negarem a

\footnotetext{
2 Os dados constantes aqui são resultados das comunicações apresentadas no Seminário Crianças e adolescentes vítimas de violência: a rede de proteção no município de Natal, promovido pelo Núcleo de Estudos Socioculturais da Infância e Adolescência/UFRN, realizado nos dias 16 e 20 de outubro de 2006. A participação dos organismos deu-se através de um de seus representantes, em duas mesas redondas compostas por 4 (quatro) organismos cada uma delas. Recorreu-se, ainda, aos dados apresentados e discutidos no Projeto Escola que Protege - Formação de Educadores (as) - subsídios para atuar no enfrentamento à violência contra crianças e adolescentes. (MEC/SECAD/Pró-Reitoria de Extensão/UFRN), do qual a primeira autora assumiu a coordenação do Módulo presencial, realizado em setembro/outubro de 2006.

3 Comunicação feita em mesa redonda do Seminário referido na nota 2.
} 
responsabilidade por seus atos, o fazem de forma perversa e acabam por culpabilizar as mães e/ou as próprias crianças. Observa, ainda, que

O pai/padrasto nessas circunstâncias envolve a filha/enteada num jogo sutil, tornando-a refém do adulto em quem confia. Ela é manipulada dentro de uma lógica na qual tudo é pré-determinado para fazê-la acreditar ser ela a culpada pelos acontecimentos. Tudo é dito $e$ feito de uma forma tal que ela não tem como se safar da armadilha cujo ritual de entrada é construído e sistematicamente repetido pelo adulto, prenunciando a iminência do abuso. A criança também o percebe, diz Furnis (1993), mas sua imaturidade estrutural não lhe permite autonomia para enfrentar o poder, a persuasão e a perspicácia do adulto. (SCHMICKLER, 2006. p. 252).

O que está em questão, portanto, é a imaturidade do sujeito e a sua incapacidade de consentimento (MACHADO, 2003).

De acordo com a legislação brasileira, o abuso sexual é incluído nos crimes contra os costumes e, portanto, punido na forma da lei.

A exploração sexual comercial de crianças e adolescentes é definida como

uma relação de mercantilização (exploração/dominação) e abuso (poder) do corpo de crianças e adolescentes (oferta) por exploradores sexuais (mercadores), organizados em redes de comercialização local e global (mercado), ou por pais ou responsáveis, e por consumidores de serviços sexuais pagos (demanda) (LEAL; LEAL, apud FALEIROS, 2006, p. 81).

Em relação aos exploradores, são clandestino que, na grande maioria das vezes, funciona legalmente, com um nome comercial de fantasia, para encobrimento das verdadeiras atividades realizadas, Assim, temos: boates, bares noturnos, hotéis e pousadas, agências de modelos e de viagem. Nessa rede de exploração, como agenciadores, participam ainda, supostos vendedores de roupas, gigolôs e motoristas de táxi.

Nos dois casos, de abuso e de exploração sexual comercial, as denúncias, embora sejam as principais que compõem o quadro de violência contra crianças e adolescentes, conforme dados apresentados a seguir, sobre a Delegacia, ainda não abrangem toda a população que sofre dessas violações. Isso porque, um número considerável de casos não é denunciado, seja por receio ou medo de punição, seja por desinformação por parte da vítima ou por descrédito em relação ao sistema de atendimento.

\section{Delegacia Especializada em Defesa da Criança e do Adolescente}

A Delegacia Especializada em Defesa da Criança e do Adolescente criada, no município de Natal/RN, em maio de 2001 e inaugurada em junho do mesmo ano, tem, dentre seus objetivos, identificadas pessoas que vivem um mercado

prevenir, investigar e reprimir as infrações penais em que a criança $e$ o adolescente figurem como sujeito passivo, adotando todas as medidas de polícia judiciária e administrativa, necessárias, com o objetivo de protegêlos contra a exploração sexual ${ }^{4} e$ os maus-tratos; planejar e executar rondas e operações policiais com o fim específico de coibir a exploração sexual $e$ os maus-tratos cometidos contra a criança e o adolescente $e^{5}$.

\footnotetext{
4 Esclarecemos que na classificação utilizada pela Delegacia, Abuso Sexual está incluído em Exploração Sexual. Não há unanimidade entre os autores sobre essa classificação.

5 Texto apresentado no Seminário, nota 2, deste trabalho.
} 
Além da atuação por vários procedimentos de enfrentamento e de combate à exploração sexual e maus tratos, individualmente ou em parceria com outros órgãos da Rede de Garantia dos Direitos, a Delegacia recebe denúncias através de um telefone, denúncias essas que são checadas para instauração do procedimento policial, quando é o caso.

Conforme sublinhado acima, a Delegacia têm enfatizado o atendimento de crianças e adolescentes que são vítimas da exploração sexual (incluindo o abuso sexual e a exploração sexual comercial ${ }^{6}$ ). Isso porque, as demandas que envolvem essa modalidade de violação dos direitos constituem em torno de $50 \%$ de todos os atendimentos. Os dados abaixo confirmam essa afirmação.

Durante o ano de 2005 foram atendidos 751 casos, assim distribuídos: maus-tratos - 314; de natureza sexual: 375 ; outros crimes: 62 . Em 2006, até outubro, o quadro é o seguinte: maus-tratos: 233; de natureza sexual: 274; outros crimes: 63. Foram atendidos, portanto, 570 casos.

Considerando o protagonista da violação, observamos que, quando se trata de maus-tratos, a mãe vem em primeiro lugar (em 2006, 126 ocorrências), seguida do pai (82) e padrasto (24). Já nos casos de exploração sexual no interior da família, o padrasto é o grande responsável (37 casos), seguido pelo pai (16 casos). Vizinhos e tios comparecem, também, como violadores (15 e 12 casos, respectivamente).

É importante observar que em 77 ocorrências há declaração de que o protagonista é uma pessoa conhecida da criança ou adolescente. Portanto, não se trata, nesses casos, de abuso sexual intrafamiliar.
Dentre as características familiares mais freqüentemente associadas ao abuso sexual, Machado destaca o modelo familiar patriarcal, em que a criança é caracterizada, socialmente, como um "grupo minoritário" e com um status social inferior, assim como mulheres e idosos; "o baixo rendimento da família; a presença de um substituto paterno; a falta de afeto físico e emocional do pai em relação à criança" (MACHADO, 2003, p. 46); a história de relações incestuosas na família, fato este apontado por vários outros autores; problemas no relacionamento do casal; punição relacionada aos temas sexuais, dentre outros.

Em relação aos fatores de vulnerabilidade relacionados à própria criança, a mesma autora recorre a vários estudos que analisam as estratégias do agente violador para "selecionar" suas vítimas. Esses estudos apontam que os abusadores

tendem a identificar e abordar crianças menos supervisionadas pela família (e.g., que andam sós) e mais carentes emocionalmente (e.g., infelizes, tímidas, socialmente isoladas), que podem ser mais facilmente cativadas pela atenção que lhes é oferecida (MACHADO, 2004, p. 47).

Quando observamos o gênero dos sujeitos vitimizados, os dados revelam que estamos diante de violência de gênero. Isto porque, somando-se os casos de violação contra meninas e adolescentes mulheres, temos 365 ocorrências contra 38 casos em meninos e adolescentes homens. No primeiro caso, temos as seguintes modalidades: atentado ao pudor (125), exploração sexual comercial (97), estupro

\footnotetext{
6 Considerando que a atividade envolve crianças e adolescentes, portanto, sujeitos em condição peculiar de desenvolvimento, condição esta caracterizada por imaturidade biopsicossocial, não é utilizado o termo "prostituição"; pesquisadores, profissionais dos serviços de garantia dos direitos das crianças e adolescentes, instituições de modo geral, têm assumido a recomendação do 1 . $^{\circ}$ Congresso Mundial contra a Exploração Sexual Comercial de Crianças, realizado em Estocolmo, em 1996 adotando a expressão "exploração sexual comercial".
} 
(38) e aliciamento (15). Já quando se trata de meninos, temos 27 ocorrências de atentado ao pudor e 11 de exploração sexual comercial.

\section{S.O.S Criança}

O Estatuto da Criança e do Adolescente, legislação à qual estamos recorrendo desde o início deste trabalho, afirma que:

a criança $e$ o adolescente têm direito à liberdade, ao respeito e à dignidade como pessoas humanas em processo de desenvolvimento [grifo nosso] (...) O direito ao respeito consiste na inviolabilidade da integridade física, psíquica e moral [grifo nosso] da criança e do adolescente, abrangendo a preservação da imagem, da identidade, da autonomia, dos valores, idéias e crenças, dos espaços e objetos pessoais (BRASIL, 1990, arts. 15 e 17, p. 19).

No entanto, conforme sinalizado em trabalho anterior, Francischini (2003), a efetivação de tais determinações, na prática, se dá de forma tímida, devido a fatores como a passividade da sociedade e a conivência da imprensa. A mesma autora afirma ainda que, apesar das pessoas se depararem diariamente com situações de violência contra crianças, e sensibilizarem-se frente ao impacto causado por tais situações de vitimização, os índices alarmantes de atos violentos, os mais diversificados, praticados contra essa população continuam a existir em proporções assustadoras. As demandas atendidas pelo Programa especificado a seguir confirmam esta afirmação.

O S.O.S Criança, no município de Natal, é um Programa de atendimento a crianças $e$ adolescentes vítimas de violência, vinculado à Fundação Estadual da Criança e do Adolescente - FUNDAC -, considerado programa de proteção especial. Essa instituição foi criada em 1994, em substituição à FEBEM, e tem por objetivo "formular e executar, em todo o Estado, uma política uniforme de proteção dos direitos da criança e do adolescente, competindo-lhe o estudo do problema e o encaminhamento das soluções" (www.fundac.rn.gov.br). Além do programa de proteção especial, desenvolvido pelo S.O.S Criança, a Fundação mantém um programa de proteção jurídico-social, através dos centros de atendimento aos jovens em conflito com a lei, e "ações suplementares" desenvolvidas através de alguns programas dirigidos a crianças e adolescentes, como, por exemplo, trabalhos com artes e possibilidades de profissionalização dos sujeitos.

Conforme sinalizado acima, o S.O.S Criança é um programa da FUNDAC que recebe denúncias de violência contra crianças e adolescentes. Considerando a faixa etária da população atendida (0-18 anos), os dados de atendimento no ano de 2003 foram os seguintes: 305 espancamentos e 801 maus-tratos. Em 2004 têm-se as seguintes denúncias atendidas: 320 espancamentos e 952 maus-tratos. O principal agente violador é a mãe, seguida pelo pai, o que reafirma os dados observados em várias pesquisas realizadas no Brasil.

No Brasil, o contingente de crianças que sofrem alguma forma de violência doméstica é alarmante, constituindo-se em um problema de saúde pública. As informações tornadas públicas pela Sociedade Internacional de Prevenção ao Abuso e Negligência na Infância indicam que, em nosso país, $12 \%$ de crianças menores de 14 anos são agredidas no interior de suas famílias, o que equivale a um contingente de 18 mil crianças agredidas por dia (CUNHA, 2004).

Segundo o Ministério da Saúde (BRASIL, 2002),

a violência intrafamiliar é toda ação ou omissão que prejudique o bemestar, a integridade física, psicológica ou a liberdade e o direito ao pleno desenvolvimento de outro membro da família. Pode ser cometida dentro 
ou fora de casa por algum membro da família, incluindo pessoas que passam a assumir a função parental, ainda que sem laços de consangüinidade, e em relação de poder à outra (p. 15).

Em 2006, recorremos aos dados em que a natureza e dimensão da violação resultaram em retirada da vítima de sua casa e em encaminhamento à instituição de abrigamento. Assim, do total de atendimentos até o presente, 73 deles (54 crianças - 2 recém-nascidos - e 19 adolescentes) foram encaminhados para abrigos. Desses 73 atendimentos, 62 são crianças ou adolescentes do sexo masculino. Segundo a coordenação local do programa, a causa mais recorrente dos encaminhamentos (36) é a recusa, por parte dos sujeitos crianças ou adolescentes, de retornarem ao convívio familiar, caracterizado por ser um ambiente de maus-tratos e atos de espancamentos, de uso de drogas (lícitas e/ou ilícitas) por parte dos pais ou padrastos/ madrastas ou de relacionamentos complicados entre filhos e pais ou cuidadores. A segunda maior causa de intervenção/encaminhamento aos abrigos (12) é: $1^{\circ}$.) a constatação de que esses sujeitos estão vivendo em contextos de risco sendo, em sua grande maioria, o convívio com pais ou cuidadores que fazem uso de drogas $e, 2^{\circ}$.) o abandono dos filhos por parte dos pais (12). Neste último caso, a coordenadora do programa relatou, tanto no Seminário a que fizemos referência na nota 2 , quanto em visitas à instituição, que, por vezes, há necessidade de arrombamento da casa para retirada da criança, o que é realizado com o auxílio da polícia e com os devidos procedimentos legais. Observou, ainda, que o abandono é caracterizado pela ausência da mãe ou pai por um período igual ou superior a 12 horas. A principal justificativa dada pelas mães é a busca de lazer. As demais causas citadas foram: roubo (2); overdose de drogas (1); negligência (2); rejeição por parte da avó (2); exploração sexual (1); recusa de atendimento médico (1); maus-tratos (1); ameaça de morte (1); expulsão de casa (1); espancamento (1); vítima de atropelamento (1); e fuga do abrigo (1).

Ressaltamos, no entanto, que muitos casos de violência contra crianças e adolescentes deixam de ser denunciados. Assim, conforme Faleiros (2006), a violação dos direitos da criança e do adolescente se acentua com a existência de

redes e pactos de silêncio, tolerância, conivência, medo, impunidade. Tanto membros da família como vizinhos, colegas, profissionais da educação, saúde, assistência, segurança, ao silenciarem sobre as situações de violência que presenciam, conhecem ou de que suspeitam, protegem o violentador (p. 95).

Isso faz com que crianças e adolescentes continuem se desenvolvendo em contextos sociais prejudiciais à sua condição peculiar de desenvolvimento. Em pesquisa desenvolvida recentemente, em que se procurou identificar a auto-estima de crianças que sofrem violência pela família, Bonavides (2005) observou que

estas crianças demonstram dificuldade de se aceitarem e se amarem de forma integral, incluindo seus sentimentos, aspectos corporais e comportamentais, e, deste modo, manifestaram o desejo de serem diferentes, em especial em relação a esses últimos aspectos. Querer ser diferente e mudar também implica estar em lugares diferentes que não seja o contexto em que vivem. (p. 262)

A autora observou, ainda, que os vínculos familiares estabelecidos pelos sujeitos em situação de violência intrafamiliar sofrem prejuízo. Segundo Assis e Avanci, (2004), 
"se houvesse um único fator que privasse emocionalmente, destruísse o ego e a autoestima e levasse a uma variedade de déficits emocionais, este fator seria a relação da criança e do adolescente com seus 'cuidadores'" (p. 161). Sentimentos negativos de tristeza, medo e culpa, associados à sua condição de vivência em um contexto permeado pela violência, conforme apontado pela literatura (RAVAZZOLA, 1999; CORSI, 2003; ASSIS, 2002) foram, também, identificados nos discursos das crianças.

\section{Considerações finais}

Conforme objetivo anunciado no início deste trabalho, procuramos apresentar e discutir as demandas e encaminhamentos de crianças e adolescentes sujeitas a condições de desenvolvimento permeadas pela violência, a partir da observação de algumas entidades que respondem pelo atendimento a essa população. Assim, elegemos o Programa Sentinela, a Delegacia Especializada e o S.O.S Criança. Com essa intenção, procuramos situar o leitor nas discussões teóricas que permearam nosso objetivo, relacionando-as com os dados apresentados, circunscritas em decorrência das limitações que um trabalho desta natureza impõe ao autor. Em uma outra investigação (FRANCIS-

\section{REFERÊNCIAS}

ABRAPIA. Maus tratos contra crianças e adolescentes: proteção e prevenção. Guia de orientações para profissionais de saúde. Rio de Janeiro: Autores e Agentes Associados, 1992.

ASSIS, S. G. Crescendo em meio à violência. In: WESTPHAL, M. F. (Org.). Violência e criança. São Paulo: Edusp. p. 115-124, 2002.

; AVANCI, J. Q. Labirinto de espelhos. A formação da auto-estima na infância e adolescência. Rio de Janeiro: FIOCRUZ, 2004.
CHINI, 2005), observamos que a submissão aos padrões de socialização impostos pela família e a concepção de que os pais têm autoridade e poder para "educar" os filhos recorrendo, com esse propósito, à violência, é o que mais ficou evidente no discurso das crianças, ao buscarem justificativas pelas ações de violência praticadas por seus cuidadores. Protagonistas de histórias de vida ambientadas em meio à violência, acabam por internalizar e, quem sabe, repetir esses padrões de socialização. $\mathrm{O}$ conseqüente comprometimento em seu desenvolvimento biopsicossocial, portanto, é uma realidade. O trabalho preventivo, portanto, é apontado como primordial, no sentido de que práticas de intervenção possam contribuir para minimizar o sofrimento que caracteriza as condições de desenvolvimento dessa população. A condição de abrigamento constitui apenas uma dentre as possibilidades. No entanto, é importante observar que o ECA "associa a condição de abrigamento à tentativa de garantir a convivência familiar e comunitária e a preservação dos vínculos familiares" (IRENE RIZZINI; IRMA RIZZINI, 2004, p. 50). Nesse sentido, a intervenção junto à família e à comunidade faz parte do paradigma adotado pelo ECA. Constituir-se enquanto prioridade na definição e adoção de políticas públicas faz da criança e do adolescente focos de intervenção que, se não estão respaldados por atenção à família, principalmente, acabam por não terem as ressonâncias desejadas.

BAZÍLIO, L. C.; KRAMER, S. Infância, educação e direitos humanos. São Paulo: Cortez Editora, 2003.

BONAVIDES, Syrleine Maria P. B. A auto-estima da criança que sofre violência física pela família. Dissertação de mestrado não publicada. Programa de Pós-Graduação em Psicologia. UFRN. 2005.

BRASIL - Ministério da Saúde. Violência Intrafamiliar - orientações para a prática em Serviço. Cadernos de Atenção Básica, Brasília, n. 8, 2002. 
Estatuto da Criança e do Adolescente. Secretaria Especial dos Direitos Humanos; Ministério da Educação, Assessoria de Comunicação Social. Brasília: MEC, ACS, 1990/2005.

CORSI, J. Maltrato y abuso en el ámbito doméstico. Fundamentos teóricos para el estudio de la violencia en las relaciones familiares. Buenos Aires: Piados, 2003.

CUNHA, M. L. C. Módulo I do Curso de Capacitação: Violência Doméstica contra Crianças e Adolescentes na Modalidade Violência Física. CECOVI - Centro de Combate à Violência Infantil, UNICEF, 2004.

FALEIROS, V. de P. Formação de educadores(as): subsídios para atuar no enfrentamento à violência contra crianças e adolescentes. Brasília: MEC/SECAD; Florianópolis: UFSC/SEaD, 2006.
FRANCISCHINI, R. As faces da Infância em contextos de violência física intrafamiliar. Perfil \& Vertentes, v. 15, n. 1, p. 1-16. Disponível em: <www.assis.unesp.br/ perfilvertentes > . Acesso em: 2003.

FUNDAC - Prefeitura Municipal de Natal. Disponível em: $<$ www.fundac.rn.gov.br $>$.

MACHADO, C. Violência e vítimas de crimes. v. 2 - Crianças. Porto/Portugal: Quarteto, 2003.

RAVAZZOLA, M. C. Historias infames: los maltratos en las relaciones. Buenos Aires: Paidós, 1999.

RIZZINI, Irene; RIZZINI, Irma. A institucionalização de crianças no Brasil - percurso histórico e desafios do presente. Rio de Janeiro: Ed. PUC/Rio; São Paulo: Loyola, 2004.

SCHMICKLER, C. M. O protagonista do abuso sexual - sua lógica e estratégias. Chapecó: Argos, 2006.

Texto recebido em 04 abr. 2008

Texto aprovado em 11 abr. 2008 